\author{
BULETINUL INSTITUTULUI POLITEHNIC DIN IAŞI \\ Publicat de \\ Universitatea Tehnică „Gheorghe Asachi” din Iaşi \\ Volumul 67 (71), Numărul 4, 2021 \\ Secţia \\ CONSTRUCTII DE MASSINI \\ DOI:10.2478/bipcm-2021-0019
}

\title{
sciendo
}

\section{EXPRESSIONS OF EULER ANGLES AS FUNCTIONS OF THE DIRECTIONAL COSINES OF THREE-ORTHOGONAL AXES IN RIGID BODY KINEMATICS - II}

\author{
BY

\section{EUGEN CORDUNEANU*} \\ "Gheorghe Asachi" Technical University of Iaşi, Romania, \\ Faculty of Machine Manufacturing and Industrial Management
}

Received: November 1, 2021

Accepted for publication: November 17, 2021

Abstract. In the rigid body kinematics, the position of the mobile frame in relation to the fixed frame is given by the base-change matrix. The elements of this orthogonal matrix are given by the Euler's angles. This paper establishes the reverse link relations between the Euler's angles and the elements of the basechange matrix (directional cosines).

Keywords: three-orthogonal axes; Euler's angles; directional cosines.

\section{Introduction}

In the rigid body kinematics, one denotes $O X Y Z$ the fixed frame and $Q X^{\prime} Y^{\prime} Z^{\prime}$ the mobile frame attached to the rigid body in motion. The unit vectors are $\bar{i}, \bar{j}, \bar{k}$ for $O X Y Z$ and $\overline{i^{\prime}}, \overline{j^{\prime}}, \overline{k^{\prime}}$ for $Q X^{\prime} Y^{\prime} Z^{\prime}$.

The Euler's angles are the position angles between the mobile frame and the fixed frame. In order to define these angles, one supposes that the frames have the same origin ( $O \equiv Q)$, considering only the rotational motion.

The Euler's angles are defined as follows (Fig. 1):

*Corresponding author; e-mail: ecorduneanu@yahoo.com (C) 2021 Eugen Corduneanu

This is an open access article licensed under the Creative Commons Attribution-NonCommercialNoDerivatives 4.0 International License (CC BY-NC-ND 4.0). 


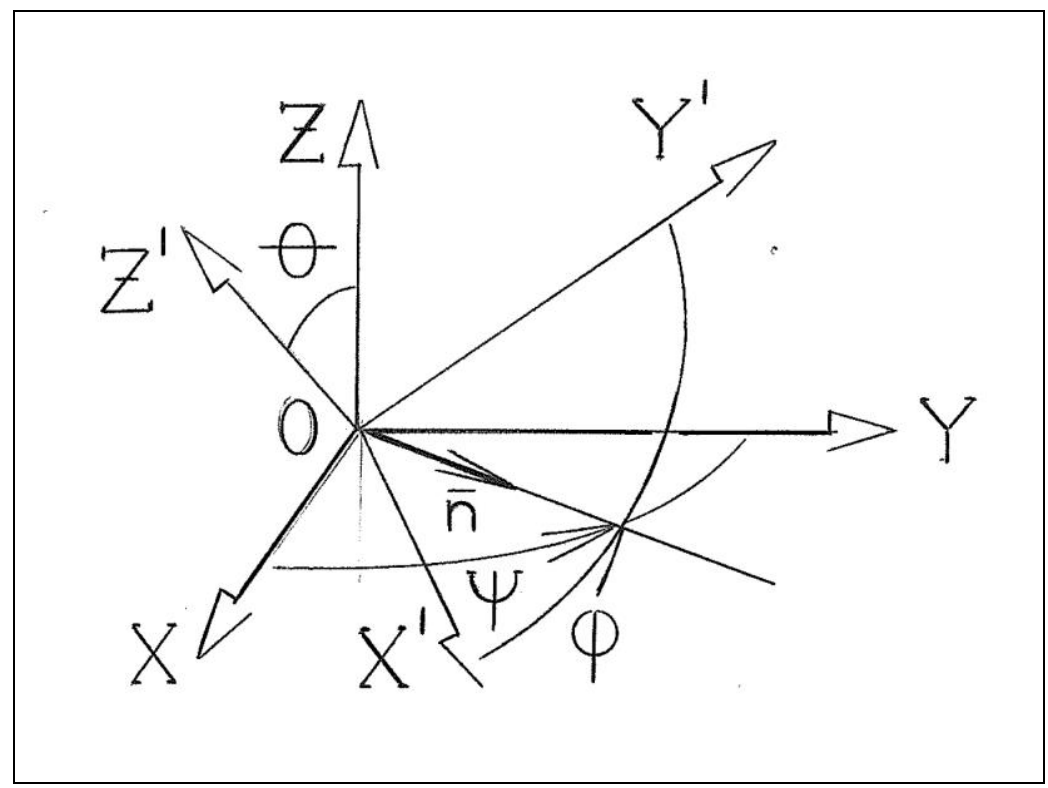

Fig. 1 - The Euler's angles.

- one defines the node line as the intersection between the $O X Y$ plane and the $O X^{\prime} Y^{\prime}$ plane,

$$
(N)=O X Y \cap O X^{\prime} Y^{\prime}
$$

- one defines the nutation angle between the $O Z$ and $O Z^{\prime}$ axes,

$$
\theta=\square\left(O Z, O Z^{\prime}\right), \quad \theta \in\left[0^{\circ}, 180^{\circ}\right] ;
$$

- one defines the unit vector of the node line using the vectorial operation

$$
\bar{n}=\frac{\bar{k} \times \overline{k^{\prime}}}{\sin \theta}, \quad \theta \neq 0^{\circ}, 180^{\circ} ;
$$

- one defines the precession angle

$$
\psi=\square(\bar{i}, \bar{n}), \quad \psi \in\left[0^{\circ}, 360^{\circ}\right),
$$

directly measured in the $O X Y$ plane; 
- one defines the own rotation angle

$$
\varphi=\square(\bar{i}, \bar{n}), \quad \varphi \in\left[0^{\circ}, 360^{\circ}\right),
$$

directly measured in the $O X^{\prime} Y^{\prime}$ plane;

According to (4) and (5), one writes the following vectorial operations:

$$
\bar{i} \times \bar{n}=\bar{k} \sin \psi, \quad \overline{i^{\prime}} \times \bar{n}=\overline{k^{\prime}} \sin \varphi
$$

The base-change matrix is a squared three-order matrix:

$$
A=\left(\begin{array}{lll}
a_{11} & a_{12} & a_{13} \\
a_{21} & a_{22} & a_{23} \\
a_{31} & a_{32} & a_{33}
\end{array}\right),
$$

with the directional cosines as elements.

The base-change matrix is an orthogonal matrix (Ibănescu and Rusu, 1998; Mangeron and Irimiciuc, 1978, Tocaci 1985, Condurache and Burlacu, 2014), that means:

$$
A^{-1}=A^{T}=\left(\begin{array}{lll}
a_{11} & a_{21} & a_{31} \\
a_{12} & a_{22} & a_{32} \\
a_{13} & a_{23} & a_{33}
\end{array}\right),
$$

where $A^{-1}$ is the reverse matrix:

$$
A \cdot A^{-1}=A^{-1} \cdot A=I_{3} .
$$

Between the column matrix of the fixed unit vectors and the column matrix of the mobile unit vectors, one writes the following relations:

$$
\begin{aligned}
& {\left[\begin{array}{lll}
\overline{i^{\prime}} & \overline{j^{\prime}} & \overline{k^{\prime}}
\end{array}\right]^{T}=A \cdot\left[\begin{array}{lll}
\bar{i} & \bar{j} & \bar{k}
\end{array}\right]^{T}} \\
& {\left[\begin{array}{lll}
\bar{i} & \bar{j} & \bar{k}
\end{array}\right]^{T}=A^{-1} \cdot\left[\begin{array}{lll}
\overline{i^{\prime}} & \overline{j^{\prime}} & \overline{k^{\prime}}
\end{array}\right]^{T}}
\end{aligned}
$$

The elements of the base-change matrix satisfie the unitary norm conditions and orthogonality conditions: 


$$
\begin{gathered}
\sum_{\mu=1}^{3} a_{\sigma \mu}^{2}=1, \quad \sigma=1,2,3 \\
\sum_{\mu=1}^{3} a_{1 \mu} a_{2 \mu}=0, \quad \sum_{\mu=1}^{3} a_{2 \mu} a_{3 \mu}=0, \quad \sum_{\mu=1}^{3} a_{3 \mu} a_{1 \mu}=0 .
\end{gathered}
$$

For the reverse matrix, one writes the same conditions:

$$
\begin{gathered}
\sum_{\mu=1}^{3} a_{\mu \sigma}^{2}=1, \quad \sigma=1,2,3 \\
\sum_{\mu=1}^{3} a_{\mu 1} a_{\mu 2}=0, \quad \sum_{\mu=1}^{3} a_{\mu 2} a_{\mu 3}=0, \quad \sum_{\mu=1}^{3} a_{\mu 3} a_{\mu 1}=0 .
\end{gathered}
$$

\section{Content}

The elements of the matrix of the directional cosines are expressed in the field literature by the Euler's angles (Ibănescu and Rusu, 1998; Mangeron and Irimiciuc, 1978).

For the unit vector of the node line, there are written the following relationships (Ibănescu and Rusu, 1998; Mangeron and Irimiciuc, 1978):

$$
\bar{n}=\bar{i} \cdot \cos \psi+\bar{j} \cdot \sin \psi=\overline{i^{\prime}} \cdot \cos \varphi+\overline{j^{\prime}} \cdot \sin \varphi
$$

By replacing the expressions of the fixed unit vectors $\bar{i}$ and $\bar{j}$ according to the Eq. (11) and relationship (8), there results that:

$$
\begin{gathered}
\left(\overline{i^{\prime}} \cdot a_{11}+\overline{j^{\prime}} \cdot a_{21}+\overline{k^{\prime}} \cdot a_{31}\right) \cdot \cos \psi+\left(\overline{i^{\prime}} \cdot a_{12}+\overline{j^{\prime}} \cdot a_{22}+\overline{k^{\prime}} \cdot a_{32}\right) \cdot \sin \psi= \\
=\overline{i^{\prime}} \cdot \cos \varphi+\overline{j^{\prime}} \cdot \sin \varphi,
\end{gathered}
$$

from which results that:

$$
\begin{aligned}
& a_{11} \cdot \cos \psi+a_{12} \cdot \sin \psi=\cos \varphi \\
& a_{21} \cdot \cos \psi+a_{22} \cdot \sin \psi=\sin \varphi \\
& a_{31} \cdot \cos \psi+a_{32} \cdot \sin \psi=0
\end{aligned}
$$


The third Eq. (18) has the following solutions:

$$
\cos \psi= \pm \frac{a_{32}}{\sqrt{a_{31}^{2}+a_{32}^{2}}}, \quad \sin \psi=\mp \frac{a_{31}}{\sqrt{a_{31}^{2}+a_{32}^{2}}} .
$$

By replacing the Eqs. (19) into the first Eq. (18), there results that:

$$
\cos \varphi=\frac{ \pm a_{11} \cdot a_{32} \mp a_{12} \cdot a_{31}}{\sqrt{a_{31}^{2}+a_{32}^{2}}}
$$

also into the second Eq. (18):

$$
\sin \varphi=\frac{ \pm a_{21} \cdot a_{32} \mp a_{22} \cdot a_{31}}{\sqrt{a_{31}^{2}+a_{32}^{2}}} .
$$

According to the definition of the unit vectors, there applies the following vectorial product:

$$
\bar{i} \times \bar{j}=\bar{k}
$$

According to the Eq. (11) and relationship (8), one writes:

$$
\begin{aligned}
& \bar{i}=a_{11} \cdot \overline{i^{\prime}}+a_{21} \cdot \overline{j^{\prime}}+a_{31} \cdot \overline{k^{\prime}} \\
& \bar{j}=a_{12} \cdot \overline{i^{\prime}}+a_{22} \cdot \overline{j^{\prime}}+a_{32} \cdot \overline{k^{\prime}}
\end{aligned}
$$

Computing the vectorial product from Eq. (22) according to the Eqs. (23), one obtains the following equality:

$$
\left(a_{21} a_{32}-a_{22} a_{31}\right) \overline{i^{\prime}}-\left(a_{11} a_{32}-a_{12} a_{31}\right) \overline{j^{\prime}}+\left(a_{11} a_{22}-a_{12} a_{21}\right) \overline{k^{\prime}}=\bar{k}
$$

Knowing the expression of the fixed unit vector $\bar{k}$ according to the Euler's angles (Ibănescu and Rusu, 1998; Mangeron and Irimiciuc, 1978):

$$
\bar{k}=-\overline{i^{\prime}} \cdot \sin \varphi \cdot \sin \psi+\overline{j^{\prime}} \cdot \cos \varphi \cdot \sin \psi+\overline{k^{\prime}} \cdot \cos \theta,
$$

one applies on this Eq. (25) a scalar multiplication with $\overline{i^{\prime}}$ and $\overline{j^{\prime}}$ : 


$$
\bar{k} \cdot \overline{i^{\prime}}=-\sin \varphi \cdot \sin \psi, \quad \bar{k} \cdot \overline{j^{\prime}}=\cos \varphi \cdot \sin \psi
$$

By the scalar multiplication of the Eq. (24) with the mobile unit vectors $\overline{i^{\prime}}$ and $\overline{j^{\prime}}$, one obtains the following:

$$
\begin{aligned}
& a_{21} a_{32}-a_{22} a_{31}=\bar{k} \cdot \overline{i^{\prime}} \\
& a_{12} a_{31}-a_{11} a_{32}=\bar{k} \cdot \overline{j^{\prime}}
\end{aligned}
$$

From the Eqs. (26) and Eqs. (27) it results:

$$
\begin{aligned}
& a_{21} a_{32}-a_{22} a_{31}=-\sin \varphi \cdot \sin \theta \\
& a_{12} a_{31}-a_{11} a_{32}=\cos \varphi \cdot \sin \theta
\end{aligned}
$$

According to the Eq. (10) and relationship (7), also to the Eq. (11) and relationship (8), one writes:

$$
\bar{k} \cdot \overline{k^{\prime}}=a_{33} .
$$

According to the definition of the nutation angle, the scalar product between the unit vectors of $O Z$ and $O Z^{\prime}$ axes is the following:

$$
\bar{k} \cdot \overline{k^{\prime}}=\cos \theta, \quad \theta=\square\left(O Z, O Z^{\prime}\right) .
$$

From the Eq. (29) and Eq. (30) there results that:

$$
\cos \theta=a_{33} .
$$

Taking into account the domain of the nutation angle from the relationship (2), one writes:

$$
\sin \theta=\sqrt{1-\cos ^{2} \theta} .
$$

Using the third Eq. (12), Eq. (31) and Eq. (32), there results that

$$
\sin \theta=\sqrt{a_{31}^{2}+a_{32}^{2}} .
$$

By replacing the Eq. (20), Eq. (21) and Eq. (33) into the Eqs. (28), there are obtained the following identities: 


$$
\begin{aligned}
& a_{21} a_{32}-a_{22} a_{31}=\mp a_{21} a_{32} \pm a_{22} a_{31} \\
& a_{12} a_{31}-a_{11} a_{32}= \pm a_{11} a_{32} \mp a_{12} a_{31}
\end{aligned},
$$

from which it results that, into the Eqs. (19), Eq. (20) and Eq. (21), there is considered the sign below.

\section{Conclusions}

In conclusion, the relations that express the Euler's angles according to the elements of the base-change matrix, that is the directional cosines, there are the relationships (19), (20), (21), (31) and (33).

For the precession angle, the Eqs. (19):

$$
\cos \psi=-\frac{a_{32}}{\sqrt{a_{31}^{2}+a_{32}^{2}}}, \sin \psi=\frac{a_{31}}{\sqrt{a_{31}^{2}+a_{32}^{2}}}
$$

For the own rotation angle, the Eq. (20) and Eq. (21):

$$
\cos \varphi=\frac{-a_{11} a_{32}+a_{12} a_{31}}{\sqrt{a_{31}^{2}+a_{32}^{2}}}, \quad \sin \varphi=\frac{-a_{21} a_{32}+a_{22} a_{31}}{\sqrt{a_{31}^{2}+a_{32}^{2}}} .
$$

For the nutation angle, the Eq. (31) and Eq. (33):

$$
\cos \theta=a_{33}, \quad \sin \theta=\sqrt{a_{31}^{2}+a_{32}^{2}} .
$$

According to the Eq. (11) and the relationship (8), one writes for the third unit vector of $O X Y Z$ :

$$
\bar{k}=a_{13} \overline{i^{\prime}}+a_{23} \overline{j^{\prime}}+a_{33} \overline{k^{\prime}} .
$$

From the Eq. (24) and Eq. (38), there results that:

$$
\begin{aligned}
& a_{13}=a_{21} a_{32}-a_{22} a_{31} \\
& a_{23}=a_{12} a_{31}-a_{11} a_{32}
\end{aligned}
$$

Also, according to the third Eq. (12), one writes that:

$$
\sqrt{a_{31}^{2}+a_{32}^{2}}=\sqrt{1-a_{33}^{2}} \text {. }
$$


By replacing the Eqs. (39) into the Eqs. (36), also by replacing the Eq. (40) into the Eqs. (35), Eqs. (36) and into the second Eq. (37), one obtains the following form for the Euler's angles:

$$
\begin{aligned}
& \cos \psi=-\frac{a_{32}}{\sqrt{1-a_{33}^{2}}}, \quad \sin \psi=\frac{a_{31}}{\sqrt{1-a_{33}^{2}}} \\
& \cos \varphi=\frac{a_{23}}{\sqrt{1-a_{33}^{2}}}, \quad \sin \varphi=-\frac{a_{13}}{\sqrt{1-a_{33}^{2}}} \\
& \cos \theta=a_{33}, \quad \sin \theta=\sqrt{1-a_{33}^{2}} .
\end{aligned}
$$

These Eqs. (41) are the same relationships from the previous paper (Corduneanu, 2019).

\section{REFERENCES}

Condurache D., Burlacu A., Dual Tensors Based Solutions for Rigid Body Motion Parametrization, Mechanism and Machine Theory, 74, 390-412 (2014).

Corduneanu E., Expressions of Euler Angles as Functions of the Directional Cosines of Three-Orthogonal Axes in Rigid Body Kinematics - I, Bul. Inst. Polit. Iaşi, 65 (69), 2, 27-35 (2019).

Ibănescu R., Rusu E., Cinematica, Editura CERMI, Iaşi, ISBN 973-9378-24-2, 1998.

Mangeron D., Irimiciuc N., Mecanica rigidelor cu aplicaţii în inginerie - vol. I Mecanica rigidului, Editura Tehnică, Bucureşti, 1978.

Tocaci E., Mecanica. Curs şi culegere de probleme, Editura Didactică şi Pedagogică, Bucureşti, 1985.

\section{EXPRESIILE UNGHIURILOR LUI EULER ÎN \\ FUNCŢIE DE COSINUSURILE DIRECTOARE ALE AXELOR REPERULUI TRIORTOGONAL ÎN CINEMATICA RIGIDULUI - II}

\section{(Rezumat)}

În cinematica solidului rigid poziția reperului mobil în raport cu reperul fix este dată de matricea schimbării de bază. Elementele matricii ortogonale sunt exprimate prin unghiurile lui Euler. Lucrarea stabileşte relaţii de legătură inversă între unghiurile lui Euler şi elementele matricii schimbării de bază (cosinusurile directoare). 